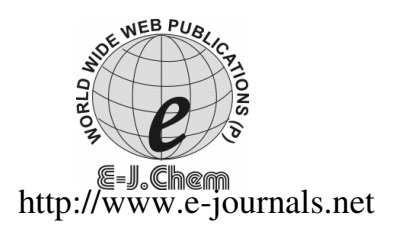

ISSN: 0973-4945; CODEN ECJHAO

E-Journal of Chemistry

2010, 7(4), 1314-1319

\title{
Preparation and Characterization of Activated Carbons from Parthenium Biomass by Physical and Chemical Activation Techniques
}

\author{
RAJESHWARI SIVARAJ*, VENCKATESH RAJENDRAN ${ }^{\S}$ \\ and G. SANGEETHA GUNALAN \\ Department of Biotechnology, School of Life Sciences, \\ Karpagam University, Eachanari, Coimbatore-641021, Tamilnadu, India. \\ ${ }^{\S}$ Faculty of Chemistry, Government Arts College, \\ Udumalpet-642126, Tamilnadu, India. \\ rajeshwarishivaraj@gmail.com
}

Received 21 January 2010; Accepted 15 March 2010

\begin{abstract}
Parthenium hysterphorous (Linn), a perennial weed of no known beneficial use was introduced as a containment of food grains imported from US with P1480 scheme. The colonization efficiency of the weed was much higher than other indigenous weeds resulting in the reduction of cultivable areas of agricultural lands. Therefore, attention was focused to find out the potential use of its biomass. In the present study the preparation and characterization of activated carbons by physical and chemical activation methods are reported and aims to prepare relatively well developed porous activated carbons as well as study various conditions and parameters that were involved during the process. Among the carbons prepared $\mathrm{ZnCl}_{2}$ impregnated carbon at the ratio of 1 was found to possess the characteristic features of an efficient adsorbent. Experimental results showed that pyrolytic and activation conditions leading to various final average temperatures had significant effect on the properties of activated carbons prepared.
\end{abstract}

Keywords: Parthenium hysterophorous (Linn), Activated carbon, Physical and Chemical activation, Characteristics, Impregnation.

\section{Introduction}

Pollution of water bodies is on increase in developing countries like India in view of direct release of untreated or partially treated industrial wastewater. Various treatment techniques have been developed involving or combining one or more of physical, chemical and biological methods. Unlike in developed countries neither enforcement of environmental laws by governmental agencies nor compliance to them by the industries is up to the level required to protect aquatic environments. In India most of the polluting industries being small-scale industries, cheap but effective technologies are being developed so as to fit in their budget and one such treatment technology involves the use of activated carbon. 
However, activated carbon prepared from conventional raw materials such as bituminous coal and peat are also expensive. Attempts have been made to prepare activated carbon from cheap and readily available materials. To date, there had been an increasing interest in the production of activated carbon from agricultural by products and industrial wastes ${ }^{1}$.

Parthenium hysterophorous (Linn), a perennial weed of no known beneficial use was introduced as a containment of food grains imported from US with PL480 scheme ${ }^{2}$. The colonization efficiency of the weed was much higher than other indigenous weeds resulting in the reduction of cultivable areas of agricultural lands. Further, efforts taken to check their proliferation and eradication became a futile exercise in India. Therefore, attention was focused to find out potential use of its biomass. In this context, this paper presents the methods of preparation of carbon from Parthenium biomass, its yield and its characteristics for potential applications in the removal of pollutants of diverse nature from polluted waters.

\section{Experimental}

Parthenium plant was collected from fallow lands in and around Coimbatore City, Tamilnadu, India. It was cut into small pieces (93 mm size app), dried in sunlight until all the moisture was evaporated. The dried material was used for the preparation of activated carbon using physical and chemical activation methods. All the reagents used were of analytical reagent grade and were obtained from SD's, Qualigen's and Merck's, Bombay, India.

\section{Nature of the adsorbent}

SEM analysis of the adsorbent was performed at the Institute of Materials, University of Nantes, The Nantes, and France.

\section{Preparation of activated carbon}

\section{Physical activation}

Parthenium was completely filled in a copper vessel of $36 \times 2.8 \mathrm{cms}$ and covered with a tight fitting lid to avoid contact with atmospheric air except with the air trapped in the voids of the material being activated. This setup was placed in a muffle furnace at 5 different terminal temperatures ranging from $400-800{ }^{\circ} \mathrm{C}$, respectively for 1 . After cooling, the material was taken out and stored in plastic containers and used for further studies.

\section{Chemical activation with zinc chloride}

Carbon were prepared from parthenium plant using $\mathrm{ZnCl}_{2}$ as an active agent at impregnation ratios from $0.0625-1.00$ where impregnation is defined as

$$
\text { Impregnation ratio }=\frac{\text { Weight of the active agent used }\left(\mathrm{ZnCl}_{2}\right)}{\text { Weight of the carbonizing material }(\text { Parthenium })}
$$

Activated carbon was prepared as described in the physical activation method after the material was impregnated with $\mathrm{ZnCl}_{2}$ at $700{ }^{\circ} \mathrm{C}$ for $1 \mathrm{~h}$ in the boiling solution of the later ${ }^{3}$. On cooling the excess of $\mathrm{ZnCl}_{2}$ on the activated carbon particles were leached out by immersing it in $1 \mathrm{M} \mathrm{HCl}$ solution for about ${ }^{4} 24 \mathrm{~h}$. It was then repeatedly washed with hot distilled water until all chlorides had disappeared from the wash water. The material was subsequently oven dried at $80{ }^{\circ} \mathrm{C}$ for $6 \mathrm{~h}$ and stored in airtight plastic containers.

\section{Chemical activation with acids}

Conc. $\mathrm{H}_{2} \mathrm{SO}_{4}, \mathrm{HCl}, \mathrm{HNO}_{3}$ and $\mathrm{H}_{3} \mathrm{PO}_{4}$ were used for the preparation of activated carbon from parthenium plant. One part of parthenium material was mixed with 1.5 part acid and $\mathrm{kept}^{5}$ in a muffle furnace for $14 \mathrm{~h}$ at $120^{\circ} \mathrm{C}$. The carbonized material was washed with distilled 
water several times to remove the free acid and soaked in $1 \%(\mathrm{w} / \mathrm{v}) \mathrm{NaHCO}_{3}$ solution overnight to remove any residual $\mathrm{acid}^{6}$. The material was then washed with double distilled water until the $\mathrm{pH}$ of the filtrate was well above 5.0. The material was dried at $80{ }^{\circ} \mathrm{C}$ for $6 \mathrm{~h}$ and stored in airtight plastic containers.

\section{Chemical activation with $\mathrm{H}_{2} \mathrm{SO}_{4}$ and ammonium persulphate $\left(\mathrm{NH}_{4} \mathrm{~S}_{2} \mathrm{O}_{8}\right)$}

Ammonium persulphate, an activating agent was used with $\mathrm{H}_{2} \mathrm{SO}_{4}$ in the preparation of activated carbons ${ }^{7}$. In this method 1 part of the material and 1.5 part of $\mathrm{H}_{2} \mathrm{SO}_{4}$ were mixed with 0.4 parts of Ammonium persulphate ${ }^{8}$ and kept in a muffle furnace at $120{ }^{\circ} \mathrm{C}$ for $14 \mathrm{~h}$ and the procedure was repeated.

\section{Results and Discussion}

The yield of parthenium carbon under different activation methods is given in Table 1.

Table 1. Carbon yield

\begin{tabular}{|c|c|c|}
\hline S. No. & Physical (thermal) activation & \\
\hline & Temperature, ${ }^{0} \mathrm{C}$ & Yield, \% \\
\hline 1. & 400 & 48.74 \\
\hline 2. & 500 & 45.39 \\
\hline 3. & 600 & 45.13 \\
\hline 4. & 700 & 38.69 \\
\hline 5. & 800 & 36.00 \\
\hline & Chemical activation & \\
\hline & Zinc chloride impregnation ratio & Yield, \% \\
\hline 6. & 0.0625 & 30.98 \\
\hline 7. & 0.125 & 36.66 \\
\hline 8. & 0.25 & 36.94 \\
\hline 9. & 0.5 & 39.07 \\
\hline \multirow[t]{2}{*}{10.} & 1.0 & 45.19 \\
\hline & Acid & Yield, \% \\
\hline 11. & $\mathrm{H}_{2} \mathrm{SO}_{4}$ & 70.00 \\
\hline 12. & $\mathrm{HCl}$ & 47.89 \\
\hline 13. & $\mathrm{HNO}_{3}$ & 37.65 \\
\hline 14. & $\mathrm{H}_{3} \mathrm{PO}_{4}$ & 46.71 \\
\hline 15. & $\mathrm{H}_{2} \mathrm{SO}_{4}+\mathrm{NH}_{4} \mathrm{~S}_{2} \mathrm{O}_{8}$ & 72.00 \\
\hline
\end{tabular}

A decrease in the yield of carbon as the terminal temperature from $400{ }^{\circ} \mathrm{C}$ to $800{ }^{\circ} \mathrm{C}$ was observed and is consist with the finding that higher the pyrolitic temperature, lower is the yield owing to the progressive loss of organic matter ${ }^{9}$. In Zinc chloride activation the percent yield increased $(30.98 \%-45.19 \%)$ with increasing impregnation ratio from 0.0625 1.00. In acid activation the order of percentage of yield was.

$$
\mathrm{H}_{2} \mathrm{SO}_{4}+\mathrm{NH}_{4} \mathrm{~S}_{2} \mathrm{O}_{8}>\mathrm{H}_{2} \mathrm{SO}_{4}>\mathrm{H}_{3} \mathrm{PO}_{4}>\mathrm{HCl}>\mathrm{HNO}_{3}
$$

Among the various methods of activation, the carbon yield was highest in acid activation ${ }^{10}$. The inhibition of tar formation and increased pyrolytic decomposition are considered as reasons for higher yield of carbon in both zinc chloride and acid activation ${ }^{11}$. However, in the latter the degree of such processes may be comparatively higher. Retention of a greater proportion of low molecular weight scission products in the carbon residue has also been considered as the reason for the enhanced yield of carbon in the case of Zinc chloride activation $^{12}$. 
Characteristics of carbon

The physical and chemical characteristics of carbons are summarized in Tables 2-4.

Table 2. Characteristics of Parthenium activated carbon prepared by physical activation (Thermal)

\begin{tabular}{|c|c|c|c|c|c|}
\hline \multirow[t]{2}{*}{ Parameter } & & \multicolumn{4}{|c|}{ Carbonization temperature, ${ }^{\circ} \mathrm{C}$} \\
\hline & 400 & 500 & 600 & 700 & 800 \\
\hline $\mathrm{pH}$ & 8.330 & 8.440 & 8.750 & 8.770 & 8.950 \\
\hline Conductivity, $\mu \mathrm{s} / \mathrm{cm}$ & 1.860 & 1.860 & 2.470 & 2.530 & 2.670 \\
\hline Specific gravity & 0.305 & 0.570 & 0.593 & 0.632 & 0.884 \\
\hline Bulk density, g/mL & 0.233 & 0.194 & 0.193 & 0.182 & 0.180 \\
\hline Porosity, \% & 23.610 & 59.120 & 60.540 & 62.500 & 73.080 \\
\hline Decolorizing power, $\mathrm{mg} / \mathrm{g}$ & 12.000 & 12.750 & 13.500 & 13.500 & 14.250 \\
\hline Ion exchange capacity, (mequ/g) & Nil & Nil & Nil & Nil & Nil \\
\hline Moisture, $\%$ & 2.600 & 2.100 & 2.000 & 1.250 & 1.000 \\
\hline Volatile Matter, \% & 20.000 & 16.570 & 12.130 & 12.190 & 10.810 \\
\hline Fixed Carbon, \% & 76.500 & 80.900 & 81.020 & 81.200 & 82.800 \\
\hline Ash, \% & 3.630 & 5.110 & 6.020 & 6.200 & 6.670 \\
\hline Surface Area (M2/g) & 155.910 & 430.610 & 498.440 & 302.070 & 292.450 \\
\hline Iron, W/W, \% & 1.200 & 1.400 & 1.300 & 1.300 & 1.300 \\
\hline Silica, W/W, \% & Nil & Nil & Nil & Nil & Nil \\
\hline Sodium, W/W, \% & 5.000 & 5.200 & 5.200 & 5.100 & 5.200 \\
\hline Potassium, W/W, \% & 3.400 & 3.600 & 6.300 & 3.600 & 3.400 \\
\hline Phosphorus, W/W, \% & 0.010 & 0.010 & 0.010 & 0.010 & 0.010 \\
\hline $\mathrm{CCl}_{4}$ activity, W/W, \% & 0.030 & 0.160 & 1.140 & 2.550 & 2.150 \\
\hline Phenol adsorption capacity,. $\mathrm{mg} / \mathrm{g}$ & 0.480 & 0.640 & 1.810 & 1.990 & 3.000 \\
\hline Matter soluble in water, $\%$ & 3.900 & 3.470 & 5.100 & 3.250 & 3010.000 \\
\hline Matter soluble in $0.25 \mathrm{M} \mathrm{HCl}, \%$ & 5.410 & 9.400 & 11.020 & 13.400 & 11.170 \\
\hline
\end{tabular}

Table 3. Characteristics of Parthenium activated carbon prepared chemical activation (Acids)

\begin{tabular}{lccccc}
\hline \multicolumn{1}{c}{ Parameter } & $\mathrm{H}_{2} \mathrm{SO}_{4}$ & $\mathrm{HCl}$ & $\mathrm{HNO}_{3}$ & $\mathrm{H}_{3} \mathrm{PO}_{4}$ & $\begin{array}{c}\mathrm{H}_{2} \mathrm{SO}_{4+} \\
\mathrm{NH}_{4} \mathrm{~S}_{2} \mathrm{O}_{8}\end{array}$ \\
\hline $\mathrm{pH}$ & 8.170 & 5.130 & 5.290 & 5.020 & 5.850 \\
Conductivity, $\mu$ s/cm & 0.410 & 0.140 & 0.270 & 0.120 & 0.190 \\
Specific gravity & 0.760 & 0.628 & 0.605 & 0.685 & 0.660 \\
Bulk density, g/mL & 0.202 & 0.172 & 0.149 & 1.144 & 1.420 \\
Porosity, \% & 73.420 & 79.030 & 71.570 & 78.250 & 78.480 \\
Decolorizing power, mg/g & 13.200 & 19.050 & 21.850 & 20.550 & 30.000 \\
Ion exchange capacity (mequ/g) & 0.250 & 0.230 & 0.270 & 0.280 & 0.450 \\
Moisture, \% & 3.300 & 2.200 & 1.700 & 3.700 & 1.200 \\
Volatile matter, \% & 57.330 & 50.334 & 59.480 & 51.750 & 57.010 \\
Fixed Carbon, \% & 31.200 & 39.900 & 31.700 & 35.100 & 34.000 \\
Ash, \% & 8.170 & 7.566 & 7.120 & 9.450 & 9.420 \\
Surface Area (M2/g) & 680.000 & 252.530 & 162.270 & 475.050 & 760.570 \\
Iron, W/W, \% & 1.200 & 1.400 & 1.300 & 1.100 & 1.200 \\
Silica, W/W, \% & $\mathrm{Nil}$ & $\mathrm{Nil}$ & $\mathrm{Nil}$ & $\mathrm{Nil}$ & $\mathrm{Nil}$ \\
Sodium, W/W, \% & 10.090 & 2.800 & 7.500 & 6.700 & 5.900 \\
Potassium, W/W, \% & 0.473 & 0.653 & 1.007 & 0.227 & 0.240 \\
Phosphorus, W/W, \% & $\mathrm{BDL}$ & $\mathrm{BDL}$ & $\mathrm{BDL}$ & $\mathrm{BDL}$ & $\mathrm{BDL}$ \\
CCl ${ }_{4}$ activity, W/W, \% & 1.190 & 0.350 & 1.200 & 0.150 & 1.350 \\
Phenol adsorption capacity, mg/g & 0.700 & 1.770 & 1.000 & 1.700 & 2.100 \\
Matter soluble in water, \% & 3.100 & 1.430 & 1.630 & 0.415 & 2.510 \\
Matter soluble in 0.25M HCl, \% & 2.480 & 2.860 & 4.880 & 2.080 & 0.500 \\
\hline
\end{tabular}


Table 4. Characteristics of Parthenium activated carbon prepared by chemical activation $\left(\mathrm{ZnCl}_{2}\right)$

\begin{tabular}{lccccc}
\hline \multicolumn{1}{c}{ Parameter } & \multicolumn{5}{c}{$\mathrm{ZnCl}_{2}$ impregnation ratio } \\
& 0.0625 & 0.125 & 0.25 & 0.5 & 1.0 \\
\hline $\mathrm{pH}$ & 6.570 & 6.550 & 6.440 & 6.390 & 6.330 \\
Conductivity, $\mu$ s/cm & 0.160 & 0.130 & 0.210 & 0.210 & 0.180 \\
Specific gravity & 0.714 & 0.801 & 0.810 & 0.812 & 0.822 \\
Bulk density, g/mL & 0.182 & 0.202 & 0.212 & 0.221 & 0.222 \\
Porosity (\%) & 74.520 & 74.400 & 73.840 & 72.780 & 72.990 \\
Decolorizing power, mg/g & 14.250 & 18.000 & 26.550 & 27.450 & 46.650 \\
Ion exchange capacity (mequ/g) & 0.120 & 0.150 & 0.350 & 0.400 & 0.610 \\
Moisture, \% & 1.100 & 2.700 & 4.200 & 5.100 & 6.230 \\
Volatile Matter, \% & 11.400 & 12.400 & 12.900 & 14.000 & 11.700 \\
Fixed Carbon, \% & 87.500 & 84.900 & 84.900 & 75.700 & 87.000 \\
Ash, \% & 7.380 & 6.780 & 6.750 & 6.680 & 6.650 \\
Surface Area, M2/g & 1089.260 & 982.420 & 941.040 & 872.880 & 839.880 \\
Iron, W/W, \% & 1.100 & 1.100 & 1.100 & 1.100 & 1.200 \\
Silica, W/W, \% & Nil & Nil & Nil & Nil & Nil \\
Sodium, W/W, \% & 1.600 & 1.400 & 1.500 & 1.400 & 1.600 \\
Potassium, W/W, \% & 1.120 & 1.120 & 1.180 & 1.120 & 1.100 \\
Phosphorus, W/W, \% & $\mathrm{BDL}$ & $\mathrm{BDL}$ & $\mathrm{BDL}$ & $\mathrm{BDL}$ & $\mathrm{BDL}$ \\
CCl ${ }_{4}$ activity, W/W, \% & 0.480 & 0.980 & 0.980 & 0.990 & 1.050 \\
Phenol adsorption capacity mg/g & 2.500 & 4.300 & 6.500 & 7.000 & 7.100 \\
Matter soluble in water, \% & 0.810 & 1.990 & 3.290 & 3.570 & 3.650 \\
Matter soluble in 0.25M HCl, \% & 10.520 & 12.390 & 12.330 & 12.040 & 9.320 \\
\hline
\end{tabular}

$B D L$ - below detection limit

In general the porosity of activated carbons was around $65 \%$ and $75 \%$ for thermal and zinc chloride activated carbons, respectively. For thermal and zinc chloride activated methods, the bulk density, decolorizing power, $\mathrm{CCl}_{4}$ activity and phenol adsorption capacity generally increased with increase in temperature and zinc chloride impregnation ratio, respectively. Higher decolorizing power, ion exchange capacity and phenol adsorption capacity of the carbons imply that, they are more suitable for adsorption of organic substances.

Surface area showed an increasing trend up to the temperature of $600{ }^{\circ} \mathrm{C}\left(155.91 \mathrm{M}^{2} / \mathrm{g}\right.$ $498.44 \mathrm{M}^{2} / \mathrm{g}$ at $800^{\circ} \mathrm{C}$ ). Similar results were reported for Ajax activated carbon ${ }^{13,14}$. According to them micropore volume increases with increase in activation temperature due to enlargement or drilling of existing pores and narrowing of pores due to shrinkage of carbon particles causes a decrease in the surface area. With increase in the impregnation ratio of $\mathrm{ZnCl}_{2}$, the surface area showed an increasing trend $\left(839.88 \mathrm{M}^{2} / \mathrm{g}-1089.26 \mathrm{M}^{2} / \mathrm{g}\right)$. Normally the porous structure is better in the case of chemical activation and the pore size distribution with the degree of impregnation, larger is the pore diameter of the carbon with consequent increase in the surface area ${ }^{15}$. The surface area of carbon prepared by acid activation decreased in the following order.

$$
\mathrm{H}_{2} \mathrm{SO}_{4}+\mathrm{NH}_{4} \mathrm{~S}_{2} \mathrm{O}_{8}>\mathrm{H}_{2} \mathrm{SO}_{4}>\mathrm{H}_{3} \mathrm{PO}_{4}>\mathrm{HCl}>\mathrm{HNO}_{3}
$$

Among the carbons prepared, $\mathrm{ZnCl}_{2}$, impregnated carbon at the ratio of 1.0 was found to exhibit the maximum surface area of $1089.26 \mathrm{M}^{2} / \mathrm{g}$. The bulk density decreased with increasing activation temperature. The observed decrease in the bulk density may be, as reported, due to the pore system becoming larger with increasing activation, a decrease in the apparent density and the constant real density of carbon ${ }^{16,17}$. The bulk density of the acid treated carbons was in the order and

$$
\mathrm{H}_{2} \mathrm{SO}_{4}>\mathrm{HCl}>\mathrm{HNO}_{3}>\mathrm{H}_{3} \mathrm{PO}_{4}>\mathrm{H}_{2} \mathrm{SO}_{4}+\mathrm{NH}_{4} \mathrm{~S}_{2} \mathrm{O}_{8}
$$


The bulk density of $\mathrm{ZnCl}_{2}$ activated carbons increased with increase in the degree of impregnation. The data pertaining to matter soluble in water (very low in all activated carbon) indicated that the carbons exhibit very low leaching properties suggesting that desorption of impurities from the carbon will be insignificant in aqueous solution ${ }^{18}$. The iron content is considerably lower in all the carbons implying that these carbons can be used in the treatment of water without the problem of iron being leached into the treated water. In view this and the observed higher fixed carbon content, surface area, decolorizing power, phenol adsorption capacity and iron exchange capacity, the activated carbon prepared by the $\mathrm{ZnCl}_{2}$ impregnation at the ratio of 1 was subject to SEM analysis to assess its nature Figure 1 and the results showed that the activated carbon is amorphous in nature. Amorphous carbons have larger surface area compared to carbons with more crystalline and well-defined structure. Larger the surface area, greater will be its adsorption capacity.
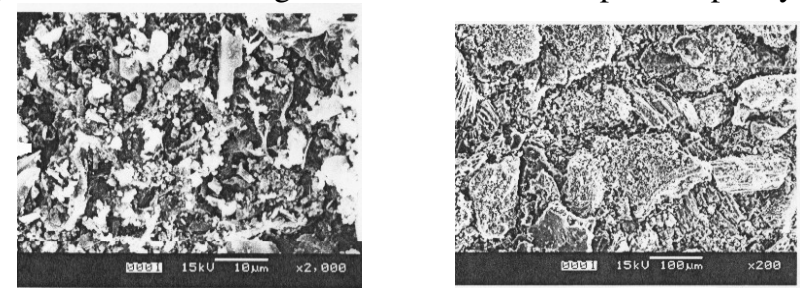

\section{Conclusion}

Figure 1. SEM analysis of $\mathrm{ZnCl}_{2}$ activated carbon sample.

In view of the high adsorbing capacity and characteristics activated carbon prepared from Parthenium plant can be effectively used for the removal of pollutants from wastewaters. As Parthenium is a noxious weed, its utilization serves the dual purpose of simultaneous eradication for better utilization.

\section{References}

1. Robinson T, Chandran B and Nigam P, Bioresour Technol., 2002b, 85, 119-124.

2. Kavita G and Nagendra B, Indian J Ecol., 2000, 27, 177-180.

3. Kadrivel K, Palanivel M, Kalpana R and Rajeswari S, Biosource Technol., 2000, 74, 263-265.

4. Calahomo V C, Garica A B, Barrera C P, Garica M J B and Gómez Corzo M, Bioresources Technol., 1993, 44(3), 229-233.

5. Khattri S D and Singh M K, Indian J Chem Technol., 1999, 6,112-116.

6. $\quad$ Rodriguez R F, Lopez-G D J and Berenguer C, Carbon, 1982, 20, 513-518.

7. Aloko D F and Adebayo G A, J Eng Appl Sci., 1984, 1, 211-222

8. Rengaraj S, Banumathi Arabindo and Murugesan V, J Sci Ind Res., 1998, 57,129

9. Ahmadpor A and Dodd, Carbon, 1995, 33, 1393-1398.

10. Bansal R C, Donnet J B, Stoeckli F and Marcel D, Active carbon, Inc., 1988, New York.

11. Hitchcock S J, Mc Enaney B and Watling S J, J Chem Tech Biotechnol.,1983, 33A, 257-163.

12. Huiping Zhang, Ying Yan and Lichun Yang. Adsorption, 2010, 16(3), 161-166.

13. Ahmadpour A and Do D D, Carbon, 1995, 33(10), 1393-1398.

14. Lopez-G D J, Valenzuela C C, Navarette G A and Gomez S V, Carbon, 1980,18, 413-428.

15. Luis K O and Luis K S, Bioresource Technol., 2000, 40(3), 215-219.

16. Rengaraj S, Banumathi A and Murugesan B, Indian J Chem Technol., 1999, 6, 1-4.

17. Meyer V, Carlsson F H H and Oellermann R A, Wat Sci Technol., 1992, 26, 1205-1211.

18. Nasser M M and El-Geundi M S, J Chem Tech Biotechnol., 1991, 50, 257-264. 


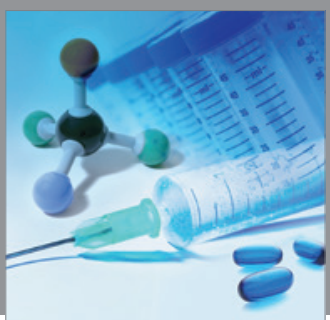

International Journal of

Medicinal Chemistry

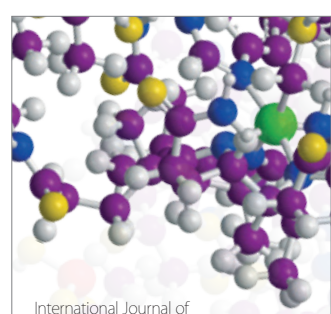

Carbohydrate Chemistry

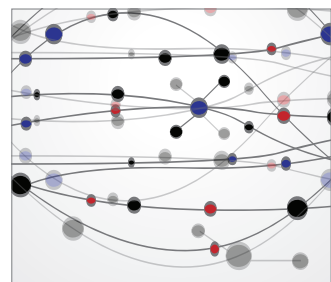

The Scientific World Journal
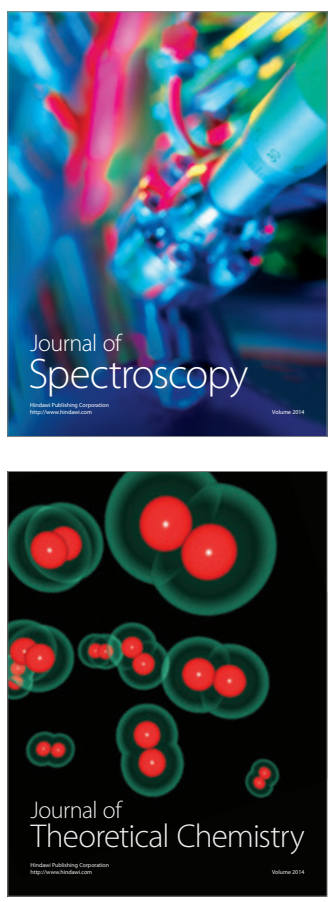
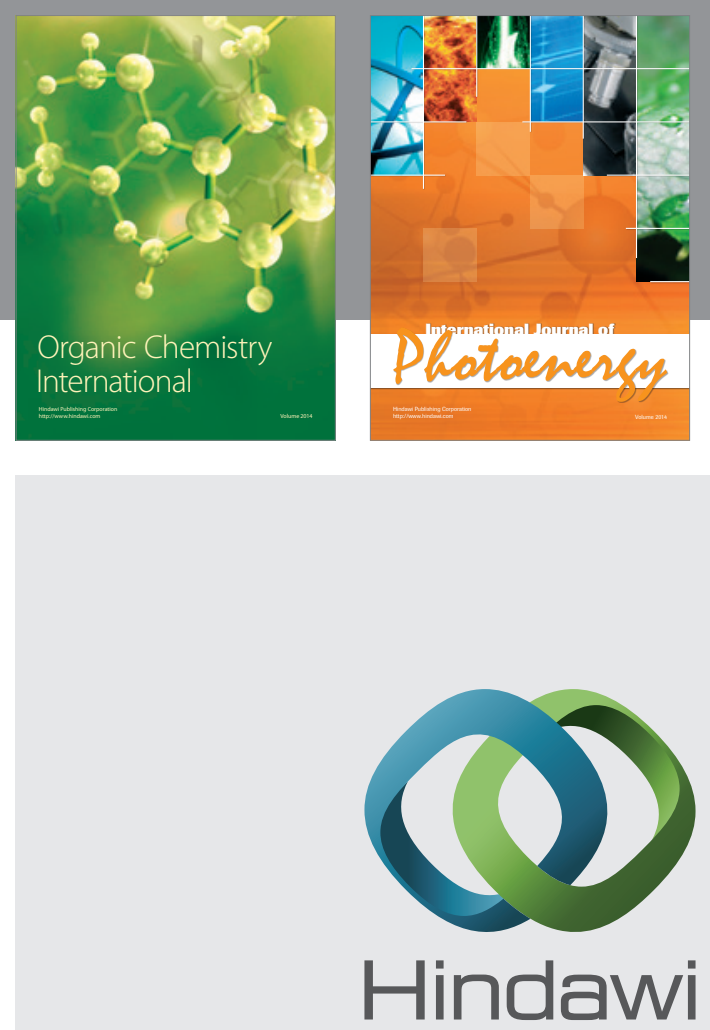

Submit your manuscripts at

http://www.hindawi.com
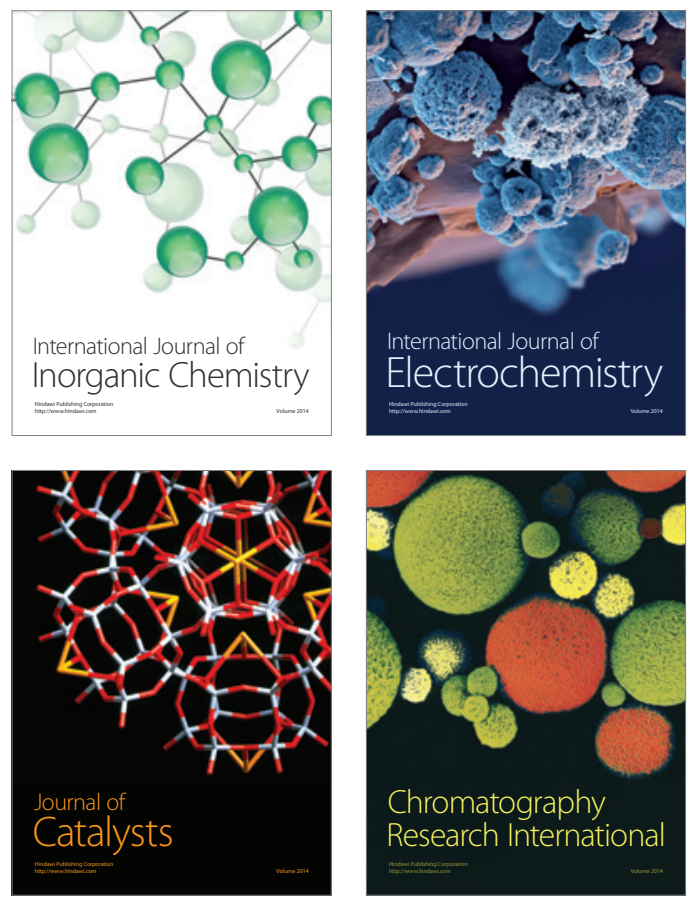
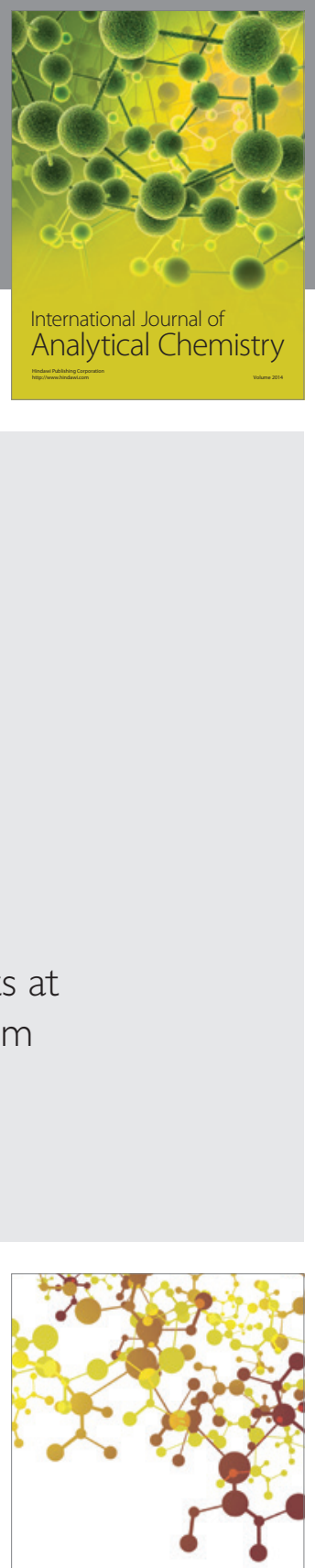

Journal of

Applied Chemistry
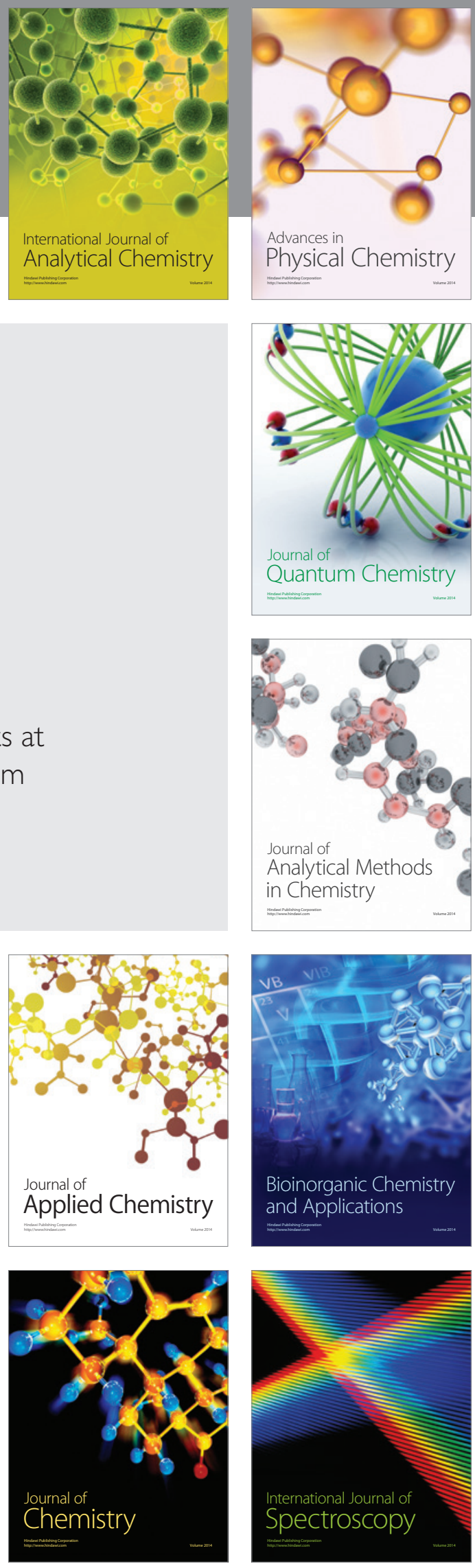